\title{
KẾT QUẢ DÀI HẠN PHẪU THUẬT CẦU NỐI ĐộNG MẠCH CHỦ NGỰC - ĐộNG MẠCH CẢNH - DƯớI ĐòN
}

\section{Đỗ Kim Quế*, Chung Giang Đông*, Nguyễn Đỗ Nhân*}

Đặt vấn đề: Hẹp các nhánh của cung động mạch chủ là một bệnh lý khá hiếm gặp, nguyên nhân đa dạng, chẩn đoán và xử trí còn nhiều khó khăn. Phẫu thuật cầu nối động mạch chủ ngực - động mạch cảnh - dưới đòn là phương pháp điều trị hiệu quả cho bệnh lý hẹp nhiều nhánh của cung động mạch chủ.

Mục tiêu nghiên cứu của chúng tôi nhằm đánh giá kết quả dài hạn của phẫu thuật cầu nối động mạch chủ ngực - động mạch cảnh - dưới đòn trong điều trị bệnh lý hẹp nhiều nhánh của cung động mạch chủ.

Đối tượng nghiên cứu: Toàn bộ bệnh nhân bị hẹp nhiều nhánh của cung động mạch chủ được điều trị phẫu thuật cầu nối động mạch chủ ngực - động mạch cảnh - dưới đòn tại Bệnh viện Chợ rẫy và bệnh viện Thống nhất trong thời gian 12 năm từ 1999 - 2011.

Phương pháp nghiên cứu: Tiền cứu. Thử nghiệm lâm sàng không đối chứng.

Chẩn đoán thương tổn dựa trên siêu âm Doppler, $\mathrm{CT}$ đa lát cắt và $\mathrm{X}$ quang động mạch.

Chỉ định phẫu thuật cho những trường hợp có triệu chứng lâm sàng, hẹp > 80\% động mạch.

Kết quả: Trong thời gian từ 10/99 đến 10/2011 chúng tôi đã điều trị phẫu thuật cầu nối động mạch chủ lên - cảnh dưới đòn cho 12 trường hợp $\mathrm{BN}$ bị hẹp nhiều nhánh của cung động mạch chủ. 4 trường hợp hẹp thân động mạch tay đầu. 4 trường hợp hẹp động mạch cảnh $\mathrm{T}$ và động mạch dưới đòn trái, 4 trường hợp hẹp cả 3 nhánh cung động mạch chủ. 12 bệnh nhân có triệu chứng thiếu máu não, 10 bệnh nhân có dấu hiệu thiếu máu nuôi tay mạn tính. 6 trường hợp hẹp do Takayashu, 6 trường hợp tổn thương do xơ vữa động mạch. Tất cả các trường hợp đều được chẩn đoán dựa trên $\mathrm{CT}$ đa lát cắt và $\mathrm{X}$ quang động mạch. 2 trường hợp hẹp $99 \%$ các trường hợp còn lại tắc hoàn toàn.

12 trường hợp được mổ với chẻ dọc phần trên xương ức. Phẫu thuật cầu nối động mạch chủ -

\footnotetext{
* Bệnh viện Thống Nhất Thành phố HCM
}

cảnh, dưới đòn cho 7 trường hợp ; cầu nối chủ cảnh, dưới đòn 2 bên cho 4 trường hợp; Cầu nối động mạch thân tay đầu - cảnh dưới đòn 1 trường hợp.

Không có trường hợp nào tử vong, 1 trường hợp nhiễm trùng vết mổ. Theo dõi tới 12 năm chưa có trường hợp nào hẹp tái phát có ý nghĩa.

Kết luận: Tắc/ hẹp nhiều nhánh của cung động mạch chủ là một tổn thương khá hiếm gặp. Đường mổ chẻ dọc phần trên xương ức cho phẫu trường tốt để thực hiện phẫu thuật cầu nối trong lồng ngực. Phẫu thuật cầu nối động mạch chủ lên cảnh dưới đòn là phương pháp diều trị đem lại kết quả tốt cho người bệnh hẹp nhiều nhánh của cung động mạch chủ.

Từ khóa: Hep các nhánh cung động mạch chủ, Cầu nối động mạch chủ ngực - cảnh - dưới đòn.

Objectives: The complex stenosis of the branches of the aortic arch is rare, it was the challenge for vascular surgeon to manage. The purpose of this study was review our experience with diagnosis and surgical treatment for complex stenosis of the branches of the aortic arch .

Methods: Prospective. Eveluate the clinical characteristics of complex stenosis of the branches of the aortic arches. Diagnosis was based on Dupplex scanning, MSCT and angiography. Intrathoracic bypass was indicated for all cases.

Results: From 10/1999 to 10/2011, twelve patients with complex stenosis of the branches of the aortic arch were treated in Choray hospital and Thong nhat hospital. 4 cases stenosis of the carotid and the subclavian artery; 4 cases have stenosis the branchiocephalic artery; and 4had stenosis all of the branches of the aortic arch. 10 cases admission because of chronic upper extremity ischemia. 12 cases had TIA. Takayashu's disease affected in 6 cases, atherosclerosis was the cause of 6 patients. All patients were diagnosed by Duplex scan, MSCT and arteriography. 2 cases with 99 percent stenosis, the others were completely occluded. 
Upper partial sternotomy were performed in all cases.; Aorto carotido-subclavian bypass in 7 cases; Aorto bi-carotid bi-subclavian bypass were performed in 4 cases; Branchiocephalo carotid and subclavian bypass in 1 case, PTFE prothesis graft was used in 2 cases. Dacron prothesis was used in the rest.

No procedure-related mortality was observed. No stroke. There are 1 wound infection, No restenosis after 12 years follow up.

Conclusions: Upper partial sternotomy is a very good approach for ascending aorto carotidosubclavian bypass operation. Ascending aorto carotido-subclavian bypass should be done for stenosis of multi-branches.

Key words: Stenosis of branches of aortic arch, Aorto - carotido-subclavian bypass.

\section{I - MỞ ĐẦU}

Hẹp các nhánh của cung động mạch chủ là một tổn thương hiếm gặp. Thường bệnh nhân nhập viện với các triệu chứng thiếu máu. Chẩn đoán chính xác và chọn lựa phương pháp điều trị thích hợp có ý nghĩa quyết định tới kết quả điều trị cho bệnh lý này.

Các nguyên nhân chính của tắc động mạch chi trên bao gồm xơ vữa động mạch, viêm động mạch không đặc hiệu, các bất thường về giải phẫu vùng nền cồ. ${ }^{(5,7)}$

Điều trị ngoại khoa hẹp/tắc các nhánh của cung động mạch chủ đã có những thay đổi lớn trong thời gian gần đây. Năm 1957, DeBakey đã báo cáo những trường hợp phục hồi lưu thông động mạch thân tay đầu và động mạch dưới đòn qua đường mở ngực. Năm 1967 Diethrich đã lần đầu tiên giới thiệu phương pháp phẫu thuật cầu nối động mạch cảnh dưới đòn ${ }^{(1,4)}$

Bachman và Kim báo cáo trường hợp tạo hình động mạch dưới đòn xuyên lòng mạch qua da (PTA) đầu tiên vào năm 1980, từ đó tới nay phương pháp này đã được xem như một phương pháp lý tưởng trong điều trị hẹp/tắc các nhánh của cung động mạch chủ. ${ }^{(1,2)}$

Tuy nhiên những trường hợp tắc hoàn toàn nhiều nhánh của cung động mạch chủ thì phẫu thuật cầu nối động mạ ch chủ ngực - cảnh dưới đòn là phương pháp ưu tiên được chọn lựa.

Trong thời gian hơn 13 năm qua chúng tôi đã điều trị cho 44 trường hợp tắc các nhánh của cung động mạch chủ mạn tính, trong đó có 12 trường hợp tắc nhiều nhánh của cung động mạch chủ được phẫu thuật cầu nối động mạch chủ ngực - cảnh dưới đòn.

Nhằm kết quả lâu dài của phẫu thuật cầu nối động mạ ch chủ ngực - cảnh dưới đòn trong điều trị hẹp nhiều nhánh của cung động mạch chủ chúng tôi đã tiến hành nghiên cứu này.

\section{II - PHƯƠNG PHÁP NGHIÊN CỨU:}

Chúng tôi nghiên cứu tiền cứu, thử nghiệm lâm sàng không đối chứng. Tất cả những bệnh nhân được chẩn đoán hẹp/tắc các nhánh của cung động mạch chủ được điều trị bằng phẫu thuật cầu nối động mạch chủ ngực - cảnh dưới đòn tại bệnh viện Chợ rẫy và bệnh viện Thống nhất TP. Hồ Chí Minh trong thời gian từ 10/1999 - 10/ 2011. được đưa vào nghiên cứu.

Chúng tôi loại trừ những trường hợp tắc động mạch dưới đòn cấp tính và bán cấp do huyết khối, những trường hợp chấn thương dập hoặc đứt động mạch.

Tất cả bệnh nhân đều được chúng tôi xác định chẩn đoán bằng siêu âm Duplex mạch máu và chụp X quang động mạch số hoá xoá nền (DSA) hoặc CT đa lát cắt.

Phẫu thuật cầu nối động mạch chủ ngực - cảnh dưới đòn được chỉ định cho những trường hợp hẹp $>90 \%$ nhiều hơn 2 nhánh của cung động mạch chủ.

Bệnh nhân được gây mê nội khí quản, Tiếp cận động mạch chủ ngực qua đường mở dọc bán phần xương ức. Động mạch cảnh và đưới đòn được bộ lộ qua đường mổ dọc bờ trước cơ ức đòn chũm và đường mổ trên xương đòn. Óng ghép mạch máu nhân tạo được nối tận bên với động mạch chủ lên hoặc tận tận vào động mạch thân tay đầu. Các đầu xa được khâu nối tận-tận hoặc tận-bên với động mạch cảnh và dưới đòn.

Đánh giá kết quả ngắn hạn về tỉ lệ tử vong, các biến chứng liên quan tới phẫu thuật và không liên quan tới phẫu thuật. 
Bệnh nhân được dùng chống kết tập tiểu cầu với aspirin ngay ngày đầu sau mổ và duy trì liên tục về sau. Kháng viêm được sử dụng khi có biểu hiện đợt cấp của bệnh Takayashu. Đường huyết và rối loạn mỡ máu được kiểm soát ở mức tối ưu.
Khám lâm sàng và siêu âm Doppler kiểm tra sau mổ 1 tháng, 3 tháng và mỗi 6 tháng sau đó để xác định tỉ lệ hẹp tái phát

\section{SỐ LIÊUU VÀ KẾT QUẢ}

Tuổi và giới:

Có 12 bệnh nhân bị hẹp/tắc các nhánh của cung động mạch chủ trong đó 4 bệnh nhân nam, tuổi trung bình là 40.2 nhỏ tuổi nhất là 15 và lớn tuổi nhất là 78 .

\section{Triệu chứng lâm sàng.}

Phần lớn bệnh nhân vào viện vì triệu chứng thiếu máu não thoáng qua. Thiếu máu nuôi tay mạn được ghi nhận trong hầu hết bệnh nhân.

$100 \%$ các trường hợp hẹp nhiều nhánh của cung động mạch chủ có biểu hiện thiếu máu não thoáng qua. Đau cách hồi chi trên là triệu chứng thường gặp với tần suất $83.3 \%$, hoại tử đầu chi chỉ thấy ở 1 trong 12 trường hợp.

Bảng 1: Triệu chứng lâm sàng.

\begin{tabular}{lll}
\hline Triệu chứng & Số trường hơp & \% \\
\hline Đau cách hồi & 10 & 83.3 \\
Hoai tử đầu ngón & 1 & 08.3 \\
Chóng mặt & 12 & 100.0 \\
Mất mạ̉h & 12 & 100 \\
Am thổi & 10 & 83.3 \\
\hline
\end{tabular}

\section{Vị trí và mức độ thương tổn:}

Chúng tôi đánh giá mức độ thương tổn dựa trên $\mathrm{X}$ quang động mạch và đối chiếu với đánh giá tổn thương trong mổ.

Trong số 12 bệnh nhân bị hẹp nhiều nhánh của cung động mạch chủ chúng tôi gặp có 4 trường hợp tổn thương ở cả 3 nhánh của cung động mạch chủ; 8 trường hợp còn lại tổn thương ở trên 2 động mạch.

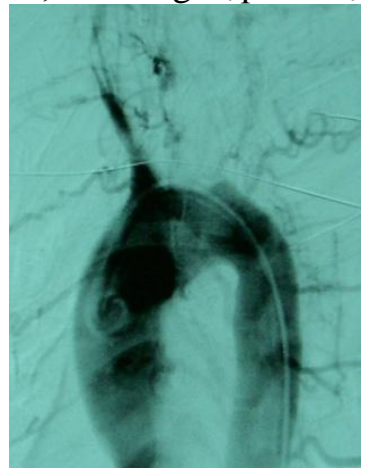

Hình 1: Tắc cả 3 nhánh của cung động mạch chủ

Bảng 2: Vị trí thương tổn.

\begin{tabular}{lll}
\hline $\boldsymbol{V}$ i trí & Số truò̀ng hop & \% \\
\hline Thân tay đầu & 4 & 33.4 \\
Cảnh trái & 6 & 50.0 \\
Cảnh phải & 4 & 33.4 \\
Dưới đòn trái & 8 & 66.7 \\
Dưới đòn phải & 6 & 50.0 \\
\hline
\end{tabular}


Bảng 3: Mức độ thương tổn.

\begin{tabular}{|c|c|c|c|}
\hline & Múc độ tổn thuơng & Số trưòng hơp & $\%$ \\
\hline & Hep dưới 80\% & 0 & 0 \\
\hline & Hẹp 80\% - 99\% & 2 & 16.7 \\
\hline & Tắc hoàn toàn & 10 & 83.3 \\
\hline & Hẹp / tắc < 2 cm & 0 & 0.0 \\
\hline & Hẹp / tắc $2-5 \mathrm{~cm}$ & 4 & 33.4 \\
\hline & Hẹp / tắc > 5 cm & 8 & 66.6 \\
\hline \multicolumn{4}{|c|}{$\begin{array}{l}\text { Tổn thưong phối hơp: } \\
\text { Bảng 4: Tốn thương phối hợp. }\end{array}$} \\
\hline & Tổn thương phối họp & Số trưòng hợp & $\%$ \\
\hline & Hẹp động mạch cột sống & 1 & 4.1 \\
\hline & Tắc động mạch chi dưới & 4 & 16.6 \\
\hline & Cao huyết áp & 10 & 83.3 \\
\hline
\end{tabular}

Tổn thương phối hơp:

Nguyên nhân:

6 trường hợp do xơ vữa động mạch được xác định qua giải phẫu bệnh lý.

6 trường hợp còn lại được nghĩ do Takayashu dựa trên tuổi bệnh nhân, đặc điểm thương tổn động mạch và kết quả giải phẫu bệnh lý có biểu hiện viêm động mạch không đặc hiệu.

\section{Phưong pháp điều trị:}

Trong 12 trường hợp tắc các nhánh của cung động mạch chủ đựơc điều trị phẫu thuật có 7 trường hợp được thực hiện cầu nối tới tất cả các nhánh của cung động mạch chủ.

Bảng 5:

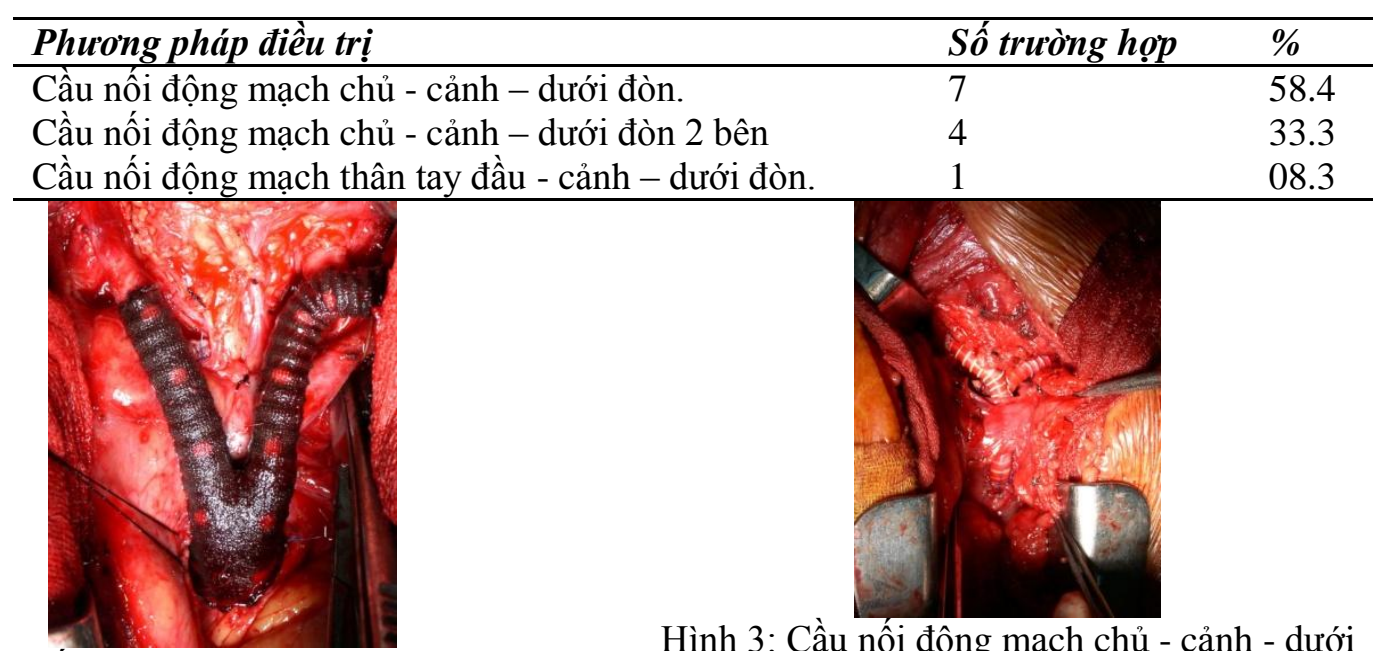

Hình 2: Cầu nối động mạch chủ - cảnh - dưới đòn 2 bên
Hình 3: Cầu nối động mạch chủ - cảnh - dưới đòn trái

\section{Kết quả điều trị}

Tất cả các trường hợp đều hết triệu chứng lâm sàng sau điều trị. Không bệnh nhân nào tử vong, không trường hợp nào phải đoạn chi. Không trường hợp nào có tổn thương thần kinh.

12 trường hợp phẫu thuật, có 1 trường hợp nhiễm trùng vết mổ.

Chúng tôi theo dõi bệnh nhân từ 3 - 144 tháng có 2 trường hợp nào xuất hiện dấu hiệu chóng mặt, 2 trường hợp có hẹp động mạch tái phát 50\% đường kính động mạch.

\section{IV - BÀN LUẬN}

So với tắc động mạch mạn tính chi dưới thì tắc động mạch mạn tính chi trên ít gặp hơn nhiều. Mặc dù ít gây hoại tử chi do có nhiều vòng nối động mạch nhưng tắc mạch chi trên gây ảnh hưởng chất lượng cuộc sống cho bệnh nhân. Giống như các nghiên cứu khác triệu chứng thiếu máu nuôi chi và thiếu máu não thoáng qua là các biểu hiện lâm sàng thương gặp. Trong nghiên cứu của chúng tôi tất cả 
các trường hợp tới nhập viện đều đã có triệu chứng lâm sàng.

Trong nghiên cứu của Bergamini ${ }^{(3)} 5 \%$ các trường hợp không có triệu chứng lâm sàng, các triệu chứng lâm sàng thường gặp là:

Bảng 6: Triệu chứng lâm sàng thường gặp

\begin{tabular}{ll}
\hline Triệu chứng & Tần suất \\
\hline Thiếu máu nuôi tay & $24 / 80$ \\
Thiếu máu não ( Steal & $28 / 80$ \\
sydrome) & \\
Phối hợp & 24 / 80 \\
Không TCLS. & $04 / 80$ \\
\hline
\end{tabular}

Ali $\mathrm{F}$. AbuRhama và cs. ${ }^{(1)}$ đã tổng kết kinh nghiệm 20 năm tại Đại học Y West Virginia với 109 bệnh nhân bị hẹp / tắc động mạch dưới đòn. $67 \%$ các trường hợp có biểu hiện thiếu máu nuôi tay, $53 \%$ các trường hợp có biểu hiện thiểu nang tuần hoàn hệ động mạch cột sống thân nền và $9 \%$ các trường hợp có hội chứng " lấy cắp máu".

Động mạch dưới đòn trái thường bị thương tổn nhất, trong nghiên cứu của chúng tôi $66.3 \%$ các trường hợp có tổn thương động mạch dưới đòn trái. Nghiên cứu của AbuRhama tỉ lệ này là $86 \%$.

Nguyên nhân của tắc động mạch mạn tính chi trên thường gặp nhất vẫn là XVĐM, các nguyên nhân khác ít gặp hơn như viêm động mạch Takayashu, viêm sợi cơ động mạch, viêm nút động mạch, các bất thường về gải phẫu, chấn thương( Thoracic outlet syndrome) ${ }^{(5,8,9)}$

$50 \%$ các trường hợp tắc các nhánh của cung động mạch chủ trong nghiên cứu này do xơ vữa động mạch, $50.0 \%$ các trường hợp do bệnh Takayashu.

\section{Chẩn đoán tắc các nhánh của cung động mạch} chủ chủ yếu dựa trên siêu âm Duplex mạch máu, CT scan, MRI. X quang động mạch vẫn là phương pháp lý tưởng giúp xác định chính xác vị trí, mức độ và hệ thống tuần hoàn bàng hệ trong tắc động mạch mạn tính chi trên cũng như chi dưới. Ngoài ra ngày nay với sự phát triển của các thủ thuật nội mạch người ta còn có thể xử trí tốt các trường hợp tắc động mạch mạn tính ngay trong khi chụp động mạch chẩn đoán.

Về điều trị tắc nhiều nhánh của cung động mạch chü:

Chỉ định can thiệp phẫu thuật cho những trường hợp có triệu chứng lâm sàng, hoăc hẹp trên $80 \%$ khẩu kính động mạch, hoặc hẹp động mạch > 50\% khẩu kính và có mảng loét trên nội mạc động mạch. $(2,4)$
Tạo hình động mạch xuyên qua lòng động mạch qua da (PTA) ngày nay đã trở thành phương pháp được lựa chọn đầu tiên cho những trường hợp hẹp động mạch dưới đòn (4). Ủu điểm của phương pháp này là tỉ lệ thành công cao, bệnh nhân ít đau, có thể vận động sớm, thời gian nằm viện ngắn, ít tốn kém, không làm tổn thương các vòng tuần hoàn bàng hệ. Tỉ lệ tử vong và biến chứng do thủ thuật thấp. Tỉ lệ hẹp tái phát khoảng $12 \%$ sau 2 năm, và những trường hợp này có thể áp dụng nong động mạch lần $2^{(4,6) \text {. }}$

Mặc dù PTA là phương pháp lý tưởng, tuy nhiên trong những trường hợp tắc hoàn toàn trên $3 \mathrm{~cm}$, hoặc hẹp trên $5 \mathrm{~cm}$, hoặc trường hợp tắc không có túi cùng thì phương pháp này không thể áp dụng được.

Cầu nối động mạch trong ngực có ưu điểm là phục hồi lưu thông động mạch theo giải phẫu, thám sát được vị trí động mạch bị thương tổn, và lưu lượng máu qua cầu nối cao, tuy nhiên tỉ lệ tử vong và biến chứng cao hơn.

Việc chọn lựa phương pháp phẫu thuật còn tùy thuộc tình trạng bệnh nhân và số nhánh động mạch bị tổn thương. ${ }^{(2,3,4)}$.

Trong nghiên cứu của chúng tôi không có tử vong, chỉ có 2 trường hợp $(9.5 \%)$ có biến chứng nhẹ.

Trường hợp tổn thương nhiều nhánh của cung động mạch chủ cần bắc cầu nối từ động mạch chủ tới phần xa của các nhánh động mạch bị tắc. Trong nghiên cứu của chúng tôi có 4 trường hợp chúng tôi bắc cầu nối động mạch chủ cảnh dưới đòn 2 bên. Đường mổ chẻ dọc nửa trên xương ức là thích hợp cho các phẫu thuật cầu nối động mạch chủ ngục cảnh - dưới đòn. Tất cả các bệnh nhân của chúng tôi đều được sử dụng đường mổ này.

Một trong những vấn đề cần nghiên cứu trong phẫu thuật cầu nối động mạch là việc chọn lựa ống ghép làm cầu nối. 10 trong 12 trường hợp phẫu thuật phục hồi lưu thông động mạch dưới đòn chúng tôi sử dụng ống Dacrone chia nhánh thay thế mạch máu, 2 trường hợp còn lại chúng tôi dùng ống ghép PTFE.

Theo AbuRahma và cs. ${ }^{(1)}$ PTFE cho kết quả lâu dài tốt nhất so với ống Dacron và tĩnh mạch tự thân khi làm cầu nối động mạch cảnh dưới đòn. Tỉ lệ ống ghép còn thông sau 5 năm là $95.2 \%$ cho ống PTFE, $83.9 \%$ cho ống Dacron, và $64.8 \%$ cho tĩnh mạch tự thân.

Kết quả lâu dài của cầu nối động mạch chủ ngực - cảnh - dưới đòn rất khả quan, tỉ lệ bệnh nhân không còn triệu chứng lâm sàng sau $1,3,5,10$ năm lần lượt là: $100 \%, 91.7 \%, 83.3 \%$, và $83.3 \%$. 


\section{V - KẾT LUÂN:}

Mặc dù tần suất khá hiếm gặp nhưng tắc động mạch dưới đòn gây ảnh hưởng không nhỏ tới sinh hoạt ủa bệnh nhân.

Chụp $\mathrm{CT}$ đa lát cắt và $\mathrm{X}$ quang động mạch là phương pháp chẩn đoán hiệu quả.

Phâ̂u thuật cầu nối động mạch chủ ngực - cảnh - dưới đòn là phương pháp điều trị an toàn và hiệu quả cho hẹp nhiều nhánh của cung động mạch chủ.

Kết quả dài hạn của phẫu thuật cầu nối động mạch chủ ngực - cảnh - dưới đòn với ống dacrone rất tốt với tỉ lệ hẹp tái phát thấp.

\section{TÀI LIỆU THAM KHẢO:}

1. Ali F. AbuRahma, Patrick A Robinson, Tucker G. Jenning, : Carotid - subclavian bypass grafting with polytetrafluoroethylene grafts for symptomatic subclavian artery stenosis or occlusion. J. Vasc. Surg. 2000; 3:411-418.

2. G.J. van Andel: Percutaneous Transluminal Angioplasty- Dotter' Procedure. Exerpta Media Amsterdam, 1976.

3. T.M. Bergamini: Surgical management of chronic upper extremities ischemia. In Vascular Diseases, D.E. Strandness, A. Breda, Churchill Livingstone Inc 1994. p524-538.
4. J. Bonn, M. C. Soulen: Thrombolysis and Angioplasty in Upper Extremities Arteries Diseases. In Vascular Diseases, D.E. Strandness, A. Breda, Churchill Livingstone Inc 1994.

5. I. Linsay, M.E. DeBakey, A.C. Beall: Diagnosis and treatment of Diseases of the Aorta. In Hurst's The Heart, 8th Ed. , 1994, p. 2163-2166.

6. Malek-AK; Rowinski-O; Ostrowski-T; Hilgertner-L; Januszewicz-M; Szostek-M: Transcutaneous balloon angioplasty in the treatment of subclavian steal syndrome. Characteristics of vertebral basal flow with transcranial Doppler technique. Pol-Tyg-Lek. 1995 Oct; 50(40-44): 19-22 7. RB Peyton, OW Isom: Occlusive diseases of branches of the aorta. In Surgery of the Chest, 6th Ed. DC. Sabiston and FC. Spencer, WB. Saunder Company 1995. p.1358-1365.

8. D.C. Sabiston: Takayashu's disease. In Sabiston Textbook of Surgery, 15th Ed. 1997, p.1679-1682.

9. HC. Urschel, MA. Razzuk: Thoracic Outlet Syndrome. In Surgery of the Chest, 6th Ed. DC. Sabiston and FC. Spencer, WB. Saunder Company 1995. p.613-633.

10. Vitti MJ, Thompson BW, Read RC, Gagne PJ, Barone GW, Barnes RW, et al. Carotid-suclavian bypass: a twenty-two year experience. J Vasc Surg 1994; 20:411- 